\title{
Analisis Forensik Jaringan Studi Kasus Serangan $S Q L$ Injection pada Server Universitas Gadjah Mada
}

\author{
Resi Utami Putri ${ }^{* 1}$, Jazi Eko Istiyanto ${ }^{2}$ \\ ${ }^{1}$ Program Studi S2 Ilkom, FMIPA, UGM, Yogyakarta \\ ${ }^{2}$ Jurusan Ilmu Komputer dan Elektronika, FMIPA UGM, Yogyakarta \\ e-mail: ${ }^{\text {11 }}$ resiutami@yahoo.com, ${ }^{2}$ jaziugm@ gmail.com
}

\begin{abstract}
Abstrak
Forensik jaringan merupakan ilmu keamanan komputer berkaitan dengan investigasi untuk menemukan sumber serangan pada jaringan berdasarkan bukti log, mengidentifikasi, menganalisis serta merekonstruksi ulang kejadian tersebut. Penelitian forensik jaringan dilakukan di Pusat Pelayanan Teknologi Informasi dan Komunikasi (PPTIK) Universitas Gadjah Mada.

Metode yang digunakan adalah model proses forensik (The Forensic Process Model) sebuah model proses investigasi forensik digital, yang terdiri dari tahap pengkoleksian, pemeriksaan, analisis dan pelaporan. Penelitian dilakukan selama lima bulan dengan mengambil data dari Intrusion Detection System (IDS) Snort. Beberapa file log digabungkan menjadi satu file log, lalu data dibersihkan agar sesuai untuk penelitian.

Berdasarkan hasil penelitian yang telah dilakukan, terdapat 68 IP address yang melakukan tindakan illegal SQL Injection pada server www.ugm.ac.id. Kebanyakan penyerang menggunakan tools SQL Injection yaitu Havij dan SQLMap sebagai tool otomatis untuk memanfaatkan celah keamanan pada suatu website. Selain itu, ada yang menggunakan skrip Python yaitu berasal dari benua Eropa yaitu di Romania.
\end{abstract}

Kata kunci-forensik jaringan, model proses forensik, SQL injection

\begin{abstract}
Network forensic is a computer security investigation to find the sources of the attacks on the network by examining log evidences, identifying, analyzing and reconstructing the incidents. This research has been conducted at The Center of Information System and Communication Service, Gadjah Mada University.

The method that used was The Forensic Process Model, a model of the digital investigation process, consisted of collection, examination, analysis, and reporting. This research has been conducted over five months by retrieving data that was collected from Snort Intrusion Detection System (IDS). Some log files were retrieved and merged into a single log file, and then the data cleaned to fit for research.

Based on the research, there are 68 IP address was that did illegal action, SQL injection, on server www.ugm.ac.id. Most of attackers using Havij and SQLmap (automated tools to exploit vulnerabilities on a website). Beside that, there was also Python script that was derived from the continent of Europe in Romania.
\end{abstract}

Keywords - Network Forensics, The Forensic Process Models, SQL Injection 


\section{PENDAHULUAN}

$\mathrm{N}$ etwork forensics (forensik jaringan) adalah kegiatan menangkap, mencatat dan menganalisis kejadian pada jaringan untuk menemukan sumber serangan keamanan atau masalah kejadian lainnya [1]. Kekuatan dari forensik adalah memungkinkan analisis dan mendapatkan kembali fakta dan kejadian dari lingkungan, karena fakta mungkin saja tersembunyi. Berbeda dari forensik pada umumnya, forensik komputer adalah kegiatan mengumpulkan dan menganalisis data dari berbagai sumber daya komputer [2]. Log yang berasal dari komputer (forensik komputer) adalah log antivirus, log database atau log dari aplikasi yang digunakan.

Forensik jaringan merupakan bagian dari forensik digital, dimana bukti ditangkap dari jaringan dan di interpretasikan berdasarkan pengetahuan dari serangan jaringan. Hal ini bertujuan untuk menemukan penyerang dan merekonstruksi tindakan serangan penyerang melalui analisis bukti penyusupan [3]. Kasus SQL Injection terjadi ketika seorang penyerang dapat memasukkan serangkaian pernyataan SQL ke query dengan memanipulasi data input ke aplikasi [4]. Sedangkan pada [5], SQL Injection adalah sebuah metodologi serangan yang menargetkan data yang berada dalam database melalui firewall yang melindungi data tersebut.

Forensik jaringan berakar dari keamanan jaringan dan deteksi penyusupan. Forensik jaringan berkaitan dengan perubahan data dari milidetik ke milidetik. Investigasi serangan cyber atau penyusupan adalah investigasi forensik jaringan. Tantangan utama yang dihadapi dari forensik jaringan adalah bagaimana caranya mempertahankan bukti kemudian digunakan di pengadilan [6].

Memerangi kejahatan internet telah menjadi porsi utama bagi agen-agen penegak hukum dan intelijen, baik nasional maupun internasional, tak terkecuali para praktisi bisnis, para pelanggan, sampai kepada end-user. Umumnya, kejahatan internet dimulai dengan mengekploitasi host-host dan jaringan komputer sehingga para penipu dan penyusup datang melintasi jaringan, terutama jaringan yang berbasiskan protokol TCP/IP [7].

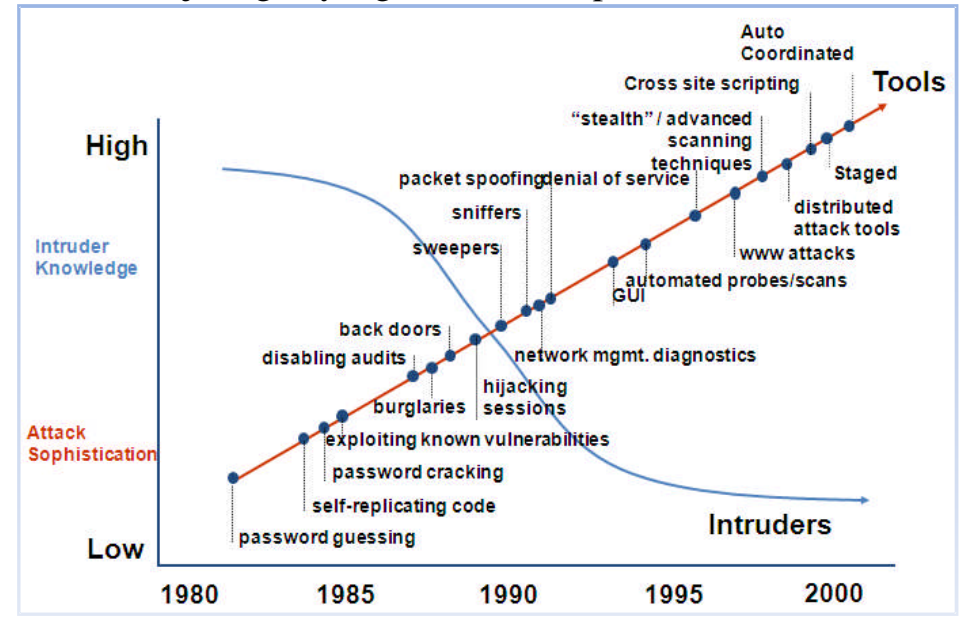

Gambar 1.1. Attack Sophistication vs Intruder Technical Knowledge [8]

Gambar 1.1. melukiskan bahwa seiring berkembangnya kecanggihan serangan dan tools justru sebaliknya pengetahuan penyusup semakin berkurang. Dikarenakan serangan yang terjadi menjadi lebih otomatis dan menyebabkan jumlah yang besar dari kerusakan. Seperti terlihat. mulai dari tahun 1980an dimulainya penebakan password di internet sampai pada waktu tool serangan terdistribusi hingga anti forensik.

Penelitian forensik jaringan terdapat pada jaringan komputer yang terdapat di Pusat Pelayanan Teknologi Informasi dan Komunikasi (PPTIK) yang merupakan pusat jaringan di Universitas Gadjah Mada. Forensik komputer merupakan hal baru dalam bidang ilmu komputer sedangkan forensik jaringan masih dalam masa pertumbuhan dalam hal teknologi [6]. Dari keterangan administrator PPTIK, kebanyakan tindakan illegal terjadi bukan berasal dari luar 
Universitas Gadjah Mada melainkan kebanyakan berasal dari dalam kampus Universitas Gadjah Mada sendiri. Maka dari itu diperlukan sebuah investigasi dan penyelidikan forensik jaringan di wilayah Universitas Gadjah Mada untuk menyelidiki kasus-kasus yang sering terjadi.

Berdasarkan semua file log yang diambil selama lebih kurang lima bulan di PPTIK, serangan yang paling banyak terjadi adalah serangan SQL Injection pada server instant messaging (im.ugm.ac.id) dan server UGM (www.ugm.ac.id). Akan tetapi, server instant messaging telah hilang dari peredaran sehingga server ugm yang diteliti pada penelitian forensik jaringan ini. Sehingga data log yang diselidiki adalah data dari serangan SQL injection yang menuju ke server Universitas Gadjah Mada (www.ugm.ac.id).

Perumusan masalah dalam penelitian forensik jaringan adalah menganalisis file log sebagai bukti bahwa telah terjadi serangan $S Q L$ Injection pada jaringan, membuat sistem forensik jaringan yang akan menganalisis kejadian pada jaringan dan membuat tools yang dapat menganalisis file log dan mengetahui port yang terbuka pada suatu server atau host.

Batasan masalah pada penelitian forensik jaringan memiliki adalah serangan yang terjadi di kampus Universitas Gadjah Mada dengan pusat jaringan terletak di Pusat Pelayanan Teknologi Informasi dan Komunikasi (PPTIK) dengan file log sebagai bukti telah terjadi serangan SQL Injection pada server Universitas Gadjah Mada (www.ugm.ac.id) yang diperoleh dari IDS (Intrusion Detection System) Snort yang digunakan oleh PPTIK UGM.

Tujuan dari penelitian forensik jaringan adalah untuk membuat sistem forensik jaringan yang dapat menganalisis kejadian serangan pada jaringan, menganalisis file log sebagai bukti tindakan illegal terhadap jaringan dan membuat tools pada server forensik jaringan yang akan menganalisis dan mengetahui port yang terbuka. Sedangkan mannfaat dari penelitian forensik jaringan adaalah dapat mengetahui port yang terbuka, mengetahui banyaknya IP address yang melakukan penyerangan, mengetahui port yang digunakan penyerang untuk masuk ke server dan dapat mengetahui tools yang digunakan oleh penyerang.

Dalam penelitian Ruchandani [3] telah melakukan eksperimen dasar forensik jaringan dengan menangkap lalu lintas paket pada jaringan, menganalisis karakteristiknya, dan mencoba untuk mengetahui aktivitas yang berbahaya dalam membantu mengidentifikasi sumber aktivitas sebagai kerusakan yang dilakukan pada jaringan menggunakan tools tcp-dump, ethereal, dan $n$ map. Disimpulkan bahwa tcp-dump, ethereal, dan n-map sangat ampuh untuk membantu menangkap dan menganalisis paket jaringan diantaranya paket sniffing dan port scanning.

Selanjutnya penelitian [9] membahas tentang ForNet, untuk memantau, mengumpulkan dan mempertahankan data untuk mendukung forensik jaringan di internet. ForNet, berbeda dari logger, menghasilkan ringkasan kompak data mentah jaringan yang dikenal sebagai sinopsis. Sinopsis menangkap informasi yang cukup untuk melakukan otopsi yang efektif. ForNet juga menerapkan strategi koleksi terdistribusi.

Penelitian [10] membahas tentang sistem logging forensik yaitu Network Processor (NP) yang dapat mengumpulkan bukti, melacak perilaku yang mencurigakan dan mengevaluasi tingkat kerusakan mesin yang diserang. Forensik sebagai ilmu keamanan baru yang berkaitan dengan penangkapan, analisis dan rekonstruksi yang bertujuan untuk membuat bukti akurat. Tugas utama dari forensik adalah analisis dan rekonstruksi. Tujuan sistem logging forensik adalah sistem yang memonitor aktivitas server pada kernel dari server sistem operasi, informasi detail pengguna dikumpulkan dari server ke Network Processor (NP) dan dikirim ke server forensik (mesin $\log$ ) dimana terdapat sistem operasi untuk memastikan kontrol akses, dan tersedianya basis data untuk merespon query dari file log disimpan ke server forensik.

Sedangkan penelitian Meghanathan [11] membahas berbagai alat dan teknik yang tersedia untuk melakukan forensik jaringan. Diantara alat yang dibahas adalah eMailTrackerPro untuk mengidentifikasi lokasi fisik dari pengirim email, Web Historian untuk mengetahui durasi kunjungan masing-masing upload file dan download dari website yang dikunjungi, packet sniffers seperti ethereal untuk menangkap dan menganalisis pertukaran data antara komputer yang berbeda di dalam jaringan. Penelitian [11] juga melakukan review teknik penelusuran IP yang berbeda untuk menandai paket dalam membantu seorang penyelidik forensik mengidentifikasi sumber-sumber serangan dan juga tentang penggunaan Honeypots 
dan Honeynets. Dapat disimpulkan untuk mendeteksi semua jenis serangan dan melakukan analisis forensik yang komprehensif, seseorang harus menyebarkan dan menganalisis efektivitas alat komersial dan mengekplorasi alat dan teknik untuk forensik jaringan.

\section{METODE PENELITIAN}

Metodologi yang digunakan dalam penelitian ini adalah model proses forensik (The Forensic Process Model) yang dilukiskan oleh gambar 2.1.

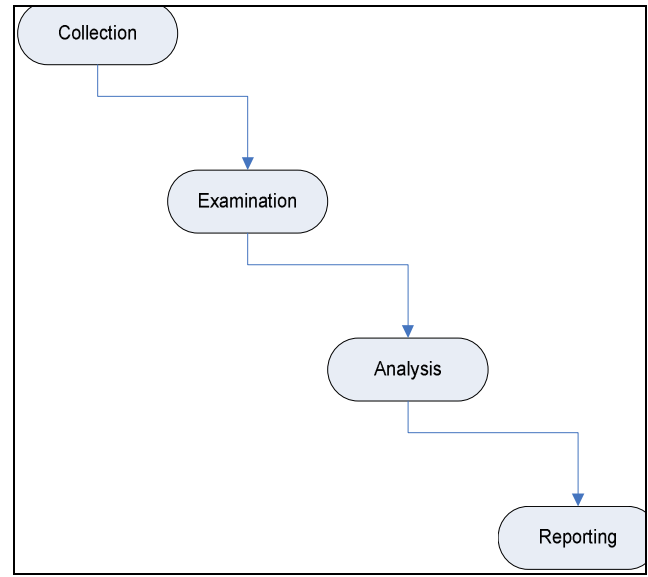

Gambar 2.1. Model proses Forensik [12]

Tahapan penelitian pada gambar 2.1. yaitu:

1. Tahap Pengkoleksian (Collection): Pada tahap ini yang dilakukan meneliti dan mencari bukti-bukti, pengenalan terhadap bukti-bukti penyusupan, dan pengumpulan bukti.

Sistem IDS Snort digunakan untuk mendeteksi serangan. Pada Snort terdapat aturan yang mengekstrak ciri dari paket yang melewati jaringan, sehingga jika ada paket yang mencurigakan dan sesuai dengan aturan lalu mengirimkan pesan alert dan menyimpannya sebagai log.

2. Tahap Pemeriksaan (Examination): Pada tahap ini, pencarian informasi yang tersembunyi dan mengungkapkan dokumentasi yang relevan. Pemeriksaan dilakukan pada file log yang telah diambil menggunakan IDS Snort. Setelah log tersimpan sebagai alert, maka log diteliti dan diperiksa. Misalnya memeriksa urutan paket.

3. Tahap analisis (Analysis): Telihat pada hasil pemeriksaan untuk nilai pembuktian pada kasus yang ada. Tahap ini digunakan untuk menjawab pertanyaan forensik yaitu serangan apa yang terjadi, IP siapa yang melakukan serangan, kapan serangan itu terjadi, dimana serangan itu terjadi, bagaimana serangan tersebut bisa terjadi, dan mengapa itu terjadi.

4. Tahap pelaporan (Reporting): Penulisan laporan mengenai proses pemeriksaan dan data yang diperoleh dari semua penyelidikan. Untuk membuat laporan tentang serangan yang terjadi pada jaringan dari hasil analisis bukti log dan setelah itu dilakukan rekontruksi aliran data dari kejadian tersebut. Tentunya tidak merusak log yang sudah ada.

\subsection{Analisis Sistem}

Topologi jaringan Universitas Gadjah Mada (UGM) adalah distributed (tersebar), pengembangan dari topologi star. PPTIK (Pusat Pelayanan Teknologi Informasi dan Komunikasi) menjadi pusat jaringan sekaligus pembagi bandwitdh dari tiap-tiap fakultas. PPTIK menjadi ISP (Internet Service Provider) bagi tiap-tiap fakultas. Pemberian bandwidth per fakultas ditentukan berdasarkan jumlah mahasiswa (lihat gambar 2.2). 


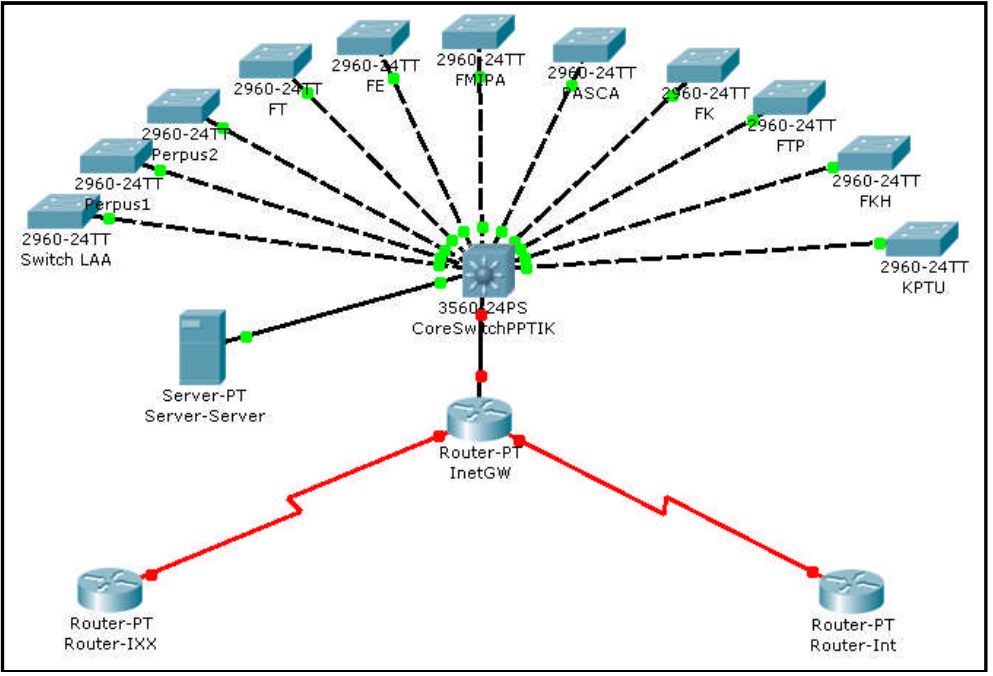

Gambar 2.2. Topologi jaringan di kampus UGM

\subsection{Rancangan Server Forensik Jaringan}

Rancangan sistem pada penelitian forensik jaringan adalah arsitektur forensik jaringan seperti ditunjukkan gambar 2.3. yang merupakan arsitektur forensik jaringan yang dibangun di Universitas Gadjah Mada. User yang ingin mengakses server yang ada di UGM melewati switch terlebih dahulu lalu masuk ke proxy kemudian server. Server IDS diletakkan sejajar dengan core switch dengan port mirroring lalu dilihat melalui PC administrator lalu data tersebut diambil dengan harddisk.

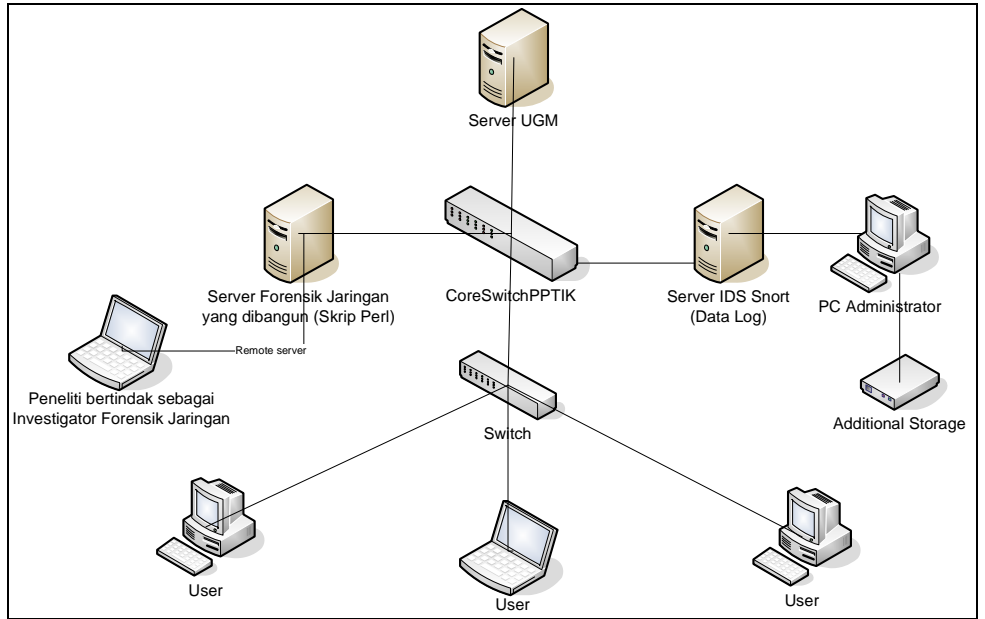

Gambar 2.3. Arsitektur forensik jaringan

\subsection{Rancangan Penelitian}

Pada rancangan penelitian (lihat gambar 2.4 pada lampiran) yang bertindak sebagai admin adalah admin PPTIK sedangkan investigator forensik jaringan adalah peneliti forensik jaringan di PPTIK. Penelitian forensik jaringan dimulai dengan mempersiapkan tool yang akan digunakan untuk penelitian, IDS Snort untuk mendeteksi penyusup pada jaringan dan script Perl untuk menganalisis paket yang ditangkap oleh Snort. Pada Snort telah dimasukan aturan sebagai pendeteksi pola pada jaringan, aturan yang digunakan pada Snort adalah aturan yang digunakan pada tempat penelitian di PPTIK telah disesuaikan yang sering terjadi di PPTIK. 


\subsection{Implementasi}

Penelitian forensik jaringan ini menggunakan server virtual machine yang disediakan oleh administrator PPTIK kepada investigator forensik jaringan. Server ini menggunakan ip statik 10.13.253.36 yang diakses melalui jaringan Universitas Gadjah Mada. Remote server dapat dihubungi dengan menggunakan protokol ssh pada port 22 sehingga proses komunikasi menjadi lebih aman karena terenkripsi, dibanding protokol telnet atau protokol lainnya yang sejenis.

\subsubsection{Algoritma Parsing Pcap}

Adapun algoritma untuk memparsing hasil log file adalah sebagai berikut.

1. Membaca file log dalam bentuk pcap.

2. Menggunakan modul untuk membaca file pcap

3. Modul yang digunakan adalah tcpdumplog.pm, Ethernet.pm, ip.pm, tcp.pm, stricts, warnings dan diagnostics.

4. Pendefinisian variabel verbose, pcap_in, file_out, dir, dump_range, lookup, dan help sebagai pilihan input.

5. Lakukan pengulangan dalam membaca masing-masing variabel

6. Tampilkan parsing

\subsubsection{Algoritma Port Scanning}

Adapun langkah-langkah algoritma yang digunakan adalah sebagai berikut.

1. Menggunakan modul socket untuk mendeteksi keberadaan port.

2. Pendefinisian variabel yang akan menampilkan host, server dan port.

3. Menampilkan hasil pencarian port yang terbuka maupun yang tertutup.

\subsubsection{Algoritma untuk Analisis File Log}

Algoritma yang digunakan adalah sebagai berikut.

1. Menggunakan modul CPAN.

2. Mendeklarasikan variabel yang digunakan.

3. Opsi untuk membaca file log pcap ke file database.

4. Membuka file untuk menyimpan header field.

5. Membaca dan memprose file pcap.

6. Sub routine untuk memproses masing-masing paket.

7. Membuat tabel IP, TCP, UDP dan ICMP.

\section{HASIL DAN PEMBAHASAN}

Hasil dari penelitian forensik jaringan dituangkan dalam Gambar 3.1. merupakan persentase IP address yang paling banyak melakukan tindakan illegal ke server UGM. Terlihat pada gambar 3.1. persentase tertinggi dimiliki oleh IP 114.79.61.33. Data tersebut diambil selama lebih kurang lima bulan, lihat tabel 3.1. 


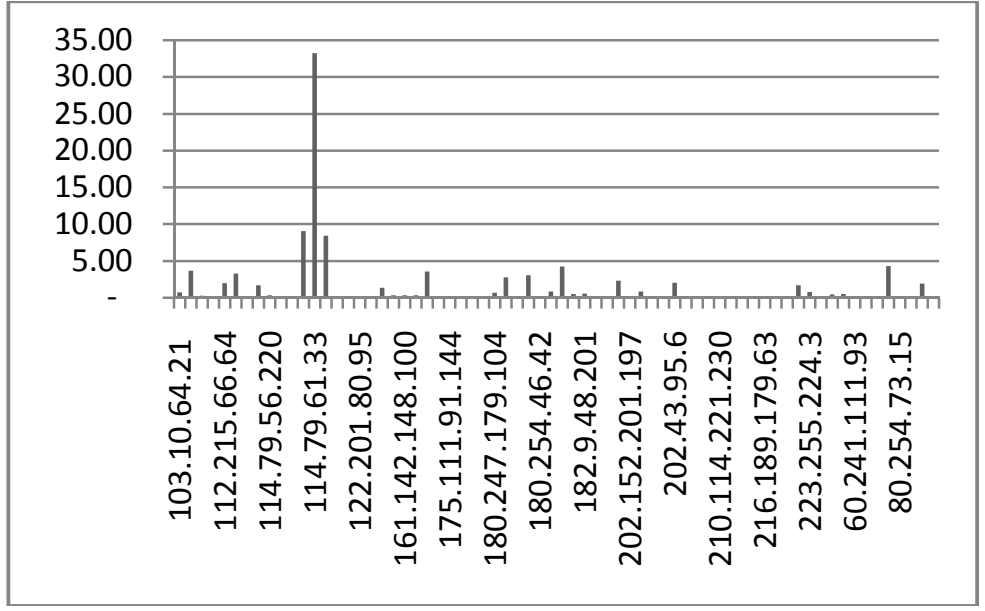

Gambar 3.1. Persentase penyerang

\subsection{Parsing File Log Pcap}

Implementasi dilakukan pada server forensik jaringan yang akan membaca file log yang telah setelah itu, dilakukan analisis terhadap file log tersebut. Guna melihat aliran header paket yang melewati jaringan, lihat gambar 3.2.

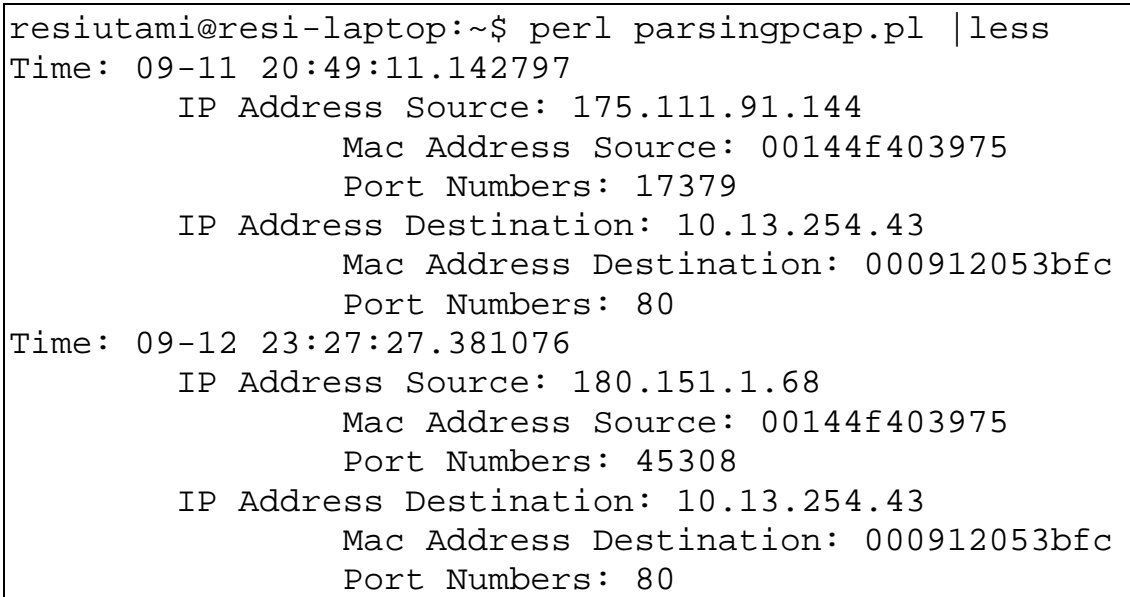

Gambar 3.2. hasil parsing terhadap file log

\subsection{Port Scanning}

Program port scanning merupakan sebuah alat untuk mengetahui port mana saja yang terbuka maupun tertutup pada sebuah server atau host. Cara menjalankannya adalah dengan cara mengetikkan perl portscan.pl lalu ip address sebuah server atau host yang ingin diketahui setelah itu nomot port yang diinginkan (lihat gambar 3.3 dan 3.4).

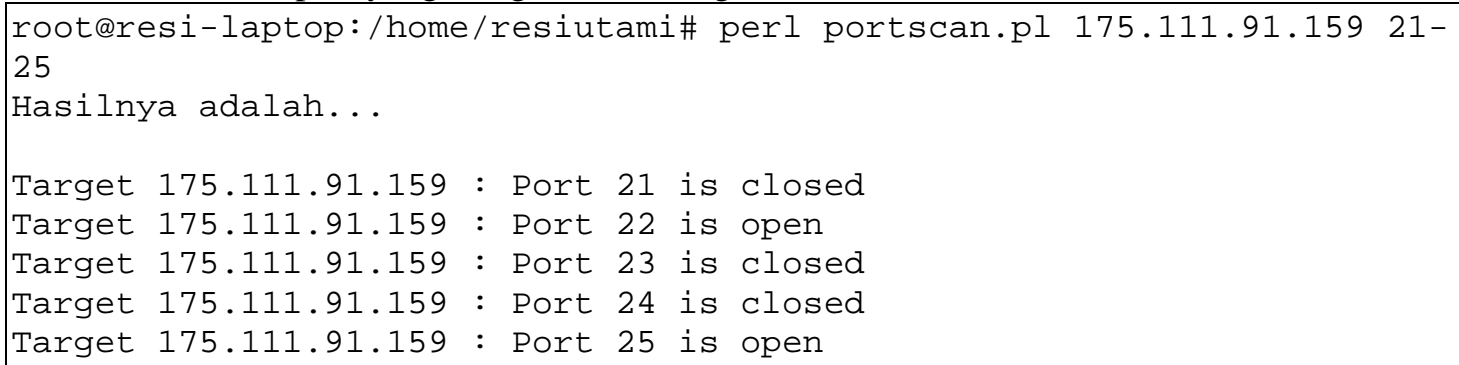

Gambar 3.4. Implementasi port scanning port 21-25 


\subsection{Analisis File Log}

Skrip terakhir adalah parsing log dan port scan digunakan untuk menganalisis file log yang telah diambil dari IDS, sehingga bisa menjawab beberapa pertanyaan seputar forensik seperti berapa ip address yang menyerang suatu server, penyerang menggunakan port apa saja untuk memasuki suatu sistem, dan beberapa hal lain yang ingin diketahui. Skrip ketiga ini menggunakan SQLite untuk melakukan analisis terhadap file log.

Proses file log menjadi sebuah basis data adalah dengan memanggil skrip pkts2db.pl diikuti dengan membuka file (-read) logfileall.pcap yaitu file log yang akan dieksekusi lalu -d (untuk membuat basis data) dan nama file log basis data yang baru. Gambar 3.5 menunjukkan perintah sql sebagai scan untuk menemukan host yang menuju ke server www.ugm.ac.id.

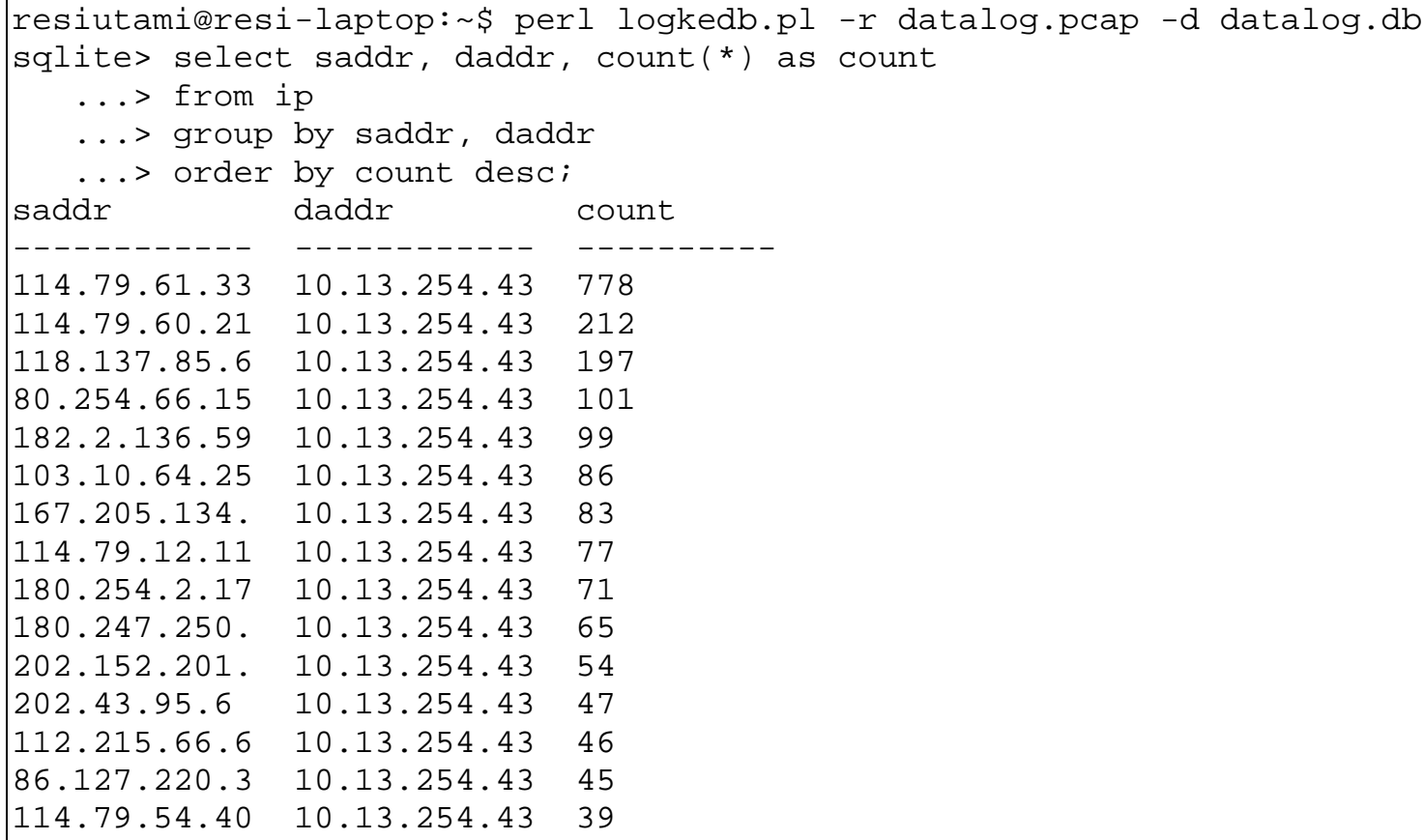

Gambar 3.5. Host yang mengunjungi situs www.ugm.ac.id

\subsection{Analisis Tool Penyerang}

Analisis tool yang digunakan oleh penyerang hanya akan dianalisis beberapa IP address saja. Pada gambar 3.6. penyerang dengan IP 182.9.48.201 diketahui berada di Indonesia dengan nama net telkomsel setelah di cek pada arin.net. Setelah di cek menggunakan tshark, tool yang digunakan penyerang adalah Havij. Havij memang cukup sering digunakan untuk sql injection (Lihat gambar 3.7.).

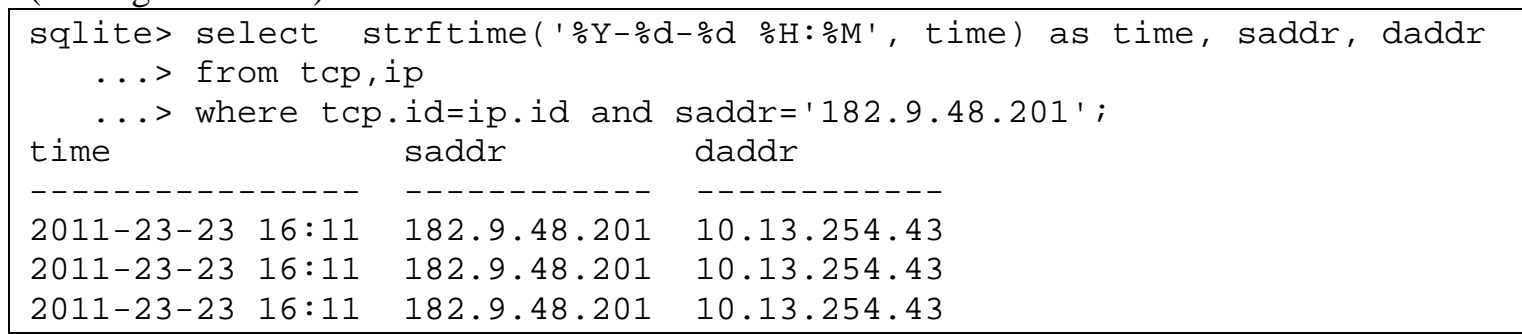

Gambar 3.6. IP penyerang pertama

182.9.48.201 10.13.254.43 Mozilla/4.0 (compatible; MSIE 7.0;

Windows NT 5.1; SV1; .NET CLR 2.0.50727) Havij

\section{Gambar 3.7. Penyerang menggunakan Havij}


Gambar 3.8 melukiskan penyerang yang memiliki IP address 114.79 .56 .220 yang diketahui berada di Indonesia dengan nama net smartaitelekom. Penyerang tersebut menggunakan sqlmap (lihat gambar 3.9) untuk melakukan penyerangan ke Universitas Gadjah Mada.

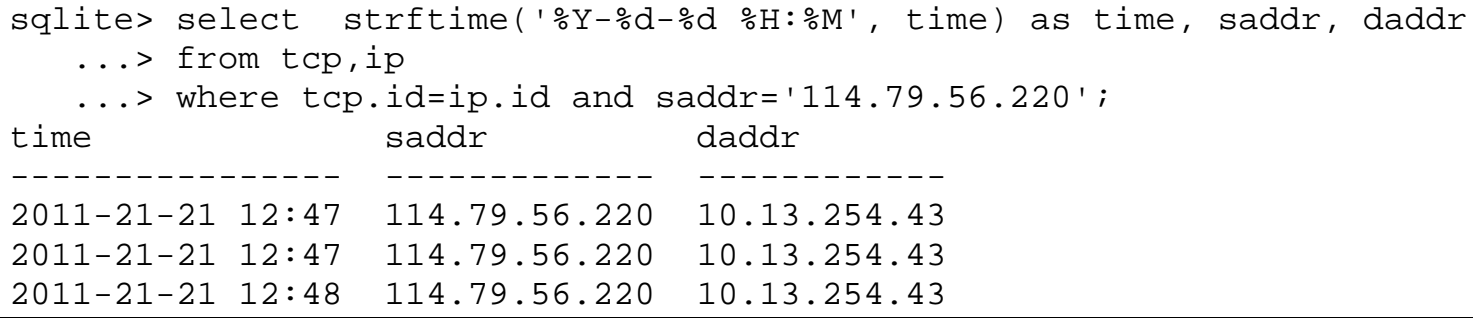

\section{Gambar 3.8. IP penyerang kedua}

$114.79 .56 .220 \quad 10.13 .254 .43$ sqlmap/1.0-dev (rNone)

(http: //www.sqlmap.org)

\section{Gambar 3.9. Penyerang menggunakan sqlmap}

Untuk penyerang terakhir dengan IP address 86.127.220.36, yang setelah ditelusuri berada di benua Eropa, tepatnya di Romania dari Universitatea Petre Andrei. Ternyata memang sering melakukan tindakan illegal hacking, pelanggaran, spam dan sebagainya. Lihat gambar 3.10 .

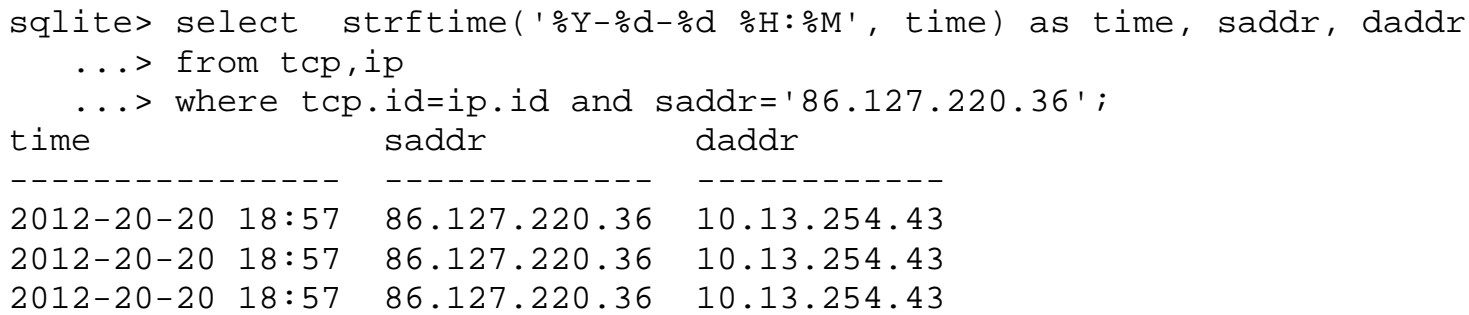

Gambar 3.10. Penyerang dari Eropa

$\begin{array}{lll}86.127 .220 .36 & 10.13 .254 .43 & \text { Python-urllib/2.7 } \\ 86.127 .220 .36 & 10.13 .254 .43 & \text { Python-urllib/2.7 }\end{array}$

Gambar 3.11. Penyerang menggunakan Python

Setelah dicek ternyata penyerang tersebut menggunakan skrip Python untuk mencari isi konten pada sebuah artikel di website UGM, lihat gambar 3.11.

\subsection{Laporan Hasil Investigasi Forensik Jaringan}

Investigasi forensik jaringan dilakukan untuk mengetahui apa saja yang terjadi pada jaringan sehingga dapat ditelusuri jejak-jejak dari penyerang. Pencarian jejak dari tindakan illegal pada jaringan di dapat dari file log. Pada penelitian forensik jaringan di UGM dilakukan dengan mengambil data pada IDS Snort yang merupakan sistem pendeteksi penyusup pada jaringan. Pada IDS Snort terdapat beberapa aturan (rule) yang digunakan dalam mendeteksi penyusup pada jaringan, aturan tersebut dipakai oleh PPTIK UGM dalam mendeteksi serangan yang terjadi.

Investigator forensik jaringan melakukan dengan membangun suatu server forensik jaringan yang terhubung ke core switch PPTIK tetapi tidak terhubung ke server IDS (lihat pada gambar 4.2). Sehingga pengambilan data dilakukan secara online dan analisis dilakukan secara offline. Pada server forensik jaringan digunakan script perl untuk menganalisis kejadian, script 
parsing pcap untuk memecah file log berdasarkan waktu, ip, mac address dan port, script port scanning untuk mengetahui port yang terbuka pada suatu server dan script untuk analisis file log dengan SQLite. Kegunaan script port scan, biasanya apabila penyerang telah berhasil masuk ke suatu sistem dengan cara SQL Injection atau mengekploitasi kelemahan web dengan basis data, penyerang akan melakukan port scan untuk mengetahui port mana saja yang terbuka. Sedangkan script SQLite sebagai alat untuk menganalisis file log sesuai dengan perintah sql yang kita masukkan. Ketiga script tersebut diletakkan pada server forensik jaringan beserta dengan modul yang digunakan.

Penelitian di PPTIK UGM dilakukan investigator forensik jaringan selama lima bulan dan telah menghasilkan file log sebesar 13MB yang telah digabung (merged) dan dibersihkan (cleaning). Dengan adanya penelitian forensik jaringan di Universitas Gadjah Mada dapat diharapkan agar dapat menjadi kesadaran bahwa cukup sulit untuk melindungi sebuah jaringan dari tindakan serangan karena yang bisa dilakukan adalah mencegahnya agar kejadian tersebut tidak terulang kembali atau diminimalisir kerusakan akibat dari serangan tersebut.

\section{KESIMPULAN}

Setelah dilakukan penelitian di PPTIK Universitas Gadjah Mada, maka dapat disimpulkan sebagai berikut:

1. Sistem forensik jaringan yang dirancang merupakan sebuah alat untuk menganalisis bukti dari file log. Sistem forensik jaringan diletakkan pada server forensik jaringan yang terhubung dengan core switch PPTIK dan memiliki IP statik 10.13.253.36. Sistem tersebut terdiri dari skrip parsing pcap, skrip port scanning dan skrip untuk merubah file log ke database.

2. Dari hasil analisis data log serangan SQL Injection yang menuju ke server Universitas Gadjah Mada (www.ugm.ac.id), serangan dilakukan kebanyakan menggunakan tools seperti Havij dan SQLMap. Selain itu, ada yang menggunakan skrip Python yaitu berasal dari benua Eropa, tepatnya di Romania.

3. Tools yang dibuat adalah parsing pcap yang dapat memecah file log dalam bentuk pcap berdasarkan tanggal, IP address, mac address dan nomor port, sedangkan tools kedua yaitu port scanning yang dapat mengetahui port yang terbuka maupun yang tertutup pada suatu host atau server, dan yang terakhir adalah tools untuk mengubah file log pcap ke bentuk database sehingga data log bisa dianalisis secara lebih mendalam.

\section{SARAN}

Untuk penelitian yang selanjutnya, disaran agar:

1. Pengembangan terhadap server forensik jaringan agar analisis hasil file log dilakukan secara online dan juga bisa langsung terhubung ke server tidak hanya offline. Maksudnya jika ada alert dari IDS (Intrusion Detection System) maka skrip untuk analisis forensik langsung otomatis menganalisis yang terjadi pada jaringan, sehingga yang dilakukan oleh pelaku dapat diketahui seketika. Disarankan untuk me-relay server IDS apabila server forensik jaringan belum terhubung.

2. Investigasi lebih lanjut terhadap IP yang melakukan serangan sehingga mengetahui asal IP address tersebut. Maksudnya jika ada serangan terhadap suatu server dari IP address tertentu maka bisa dilacak asal serangan pada saat itu juga, dikarenakan sistem forensik jaringan tersebut sudah online.

3. Lakukan penelitian untuk serangan SQL Injection lebih lanjut apabila serangan yang terjadi pada jaringan bukan hanya menggunakan sebuah tool otomatis seperti Havij maupun SQLmap, tapi juga menggunakan skrip seperti perl dan python atau alat yang lebih canggih lainnya.

IJCCS Vol. 6, No. 2, July 2012: $101-112$ 


\section{UCAPAN TERIMA KASIH}

Penulis mengucapkan terima kasih kepada kedua orang tua, dosen di Universitas Gadjah Mada dan Universitas Bina Darma serta berbagai pihak yang membantu.

\section{DAFTAR PUSTAKA}

[1] Singh, O., 2009. Network Forensics. Indian Computer Response Team (CERT-In) Department of Information Technology, New Delhi, India.

[2] Sulianta, F., 2008, Komputer Forensik. Jakarta : PT. Elex Media Komputindo.

[3] Ruchandani, B., Kumar, M., Kumar, A., Kumari, K., Sinha., A.,K., 2006, Ekperimentation In Network Forensics Analysis. Proceedings of the Term Paper Series under CDACCNIE Bangalore, India, December 2006.

[4] Anley, C., 2002, Advanced SQL Injection in SQL Server Applications. An NGSSoftware Insight Security Research (NISR) Publications: Next Generation Security Software Ltd.

[5] Anonymous, 2011, Ethical Hacking. EC-Council.

[6] Volonino, L. and Reynaldo A., 2008, Computer Forensics For Dummies. Indianapolis, Indiana : Wiley Publishing, Inc.

[7] Rafiudin, R., 2009, Investigasi Sumber-sumber Kejahatan Internet: Internet Forensik. Yogyakarta : Penerbit Andi.

[8] Shimeall, T., 2002, Cyberterrorism.Software Engineering Institute. CERT Center: Pittsburgh.

[9] Shanmugasundaram, K., 2005, ForNet: A Distributed Forensic Network. Polytechnic University.

[10] Park, T.K., Ra, I., 2008. Design and Evaluation of A Network Forensic Logging system. International Conference on Convergence and Hybrid Information Technology. Third 2008 IEEE.

[11] Meghanathan, N., Allam, S., R., Moore, L., A., 2009. Tools and Techniques For Network Forensics. International Journal of Network Security \& ItsApplications (IJNSA), Volume .1, No.1,April 200914.

[12] Baryamureeba,V., Tushabe, F., 2004, The Enhanced Digital Investigation Process Model. Proceedings of the Fourth Digital Forensic Research Workshop, May 27. 
LAMPIRAN

Forensik Jaringan di Universitas Gadjah Mada

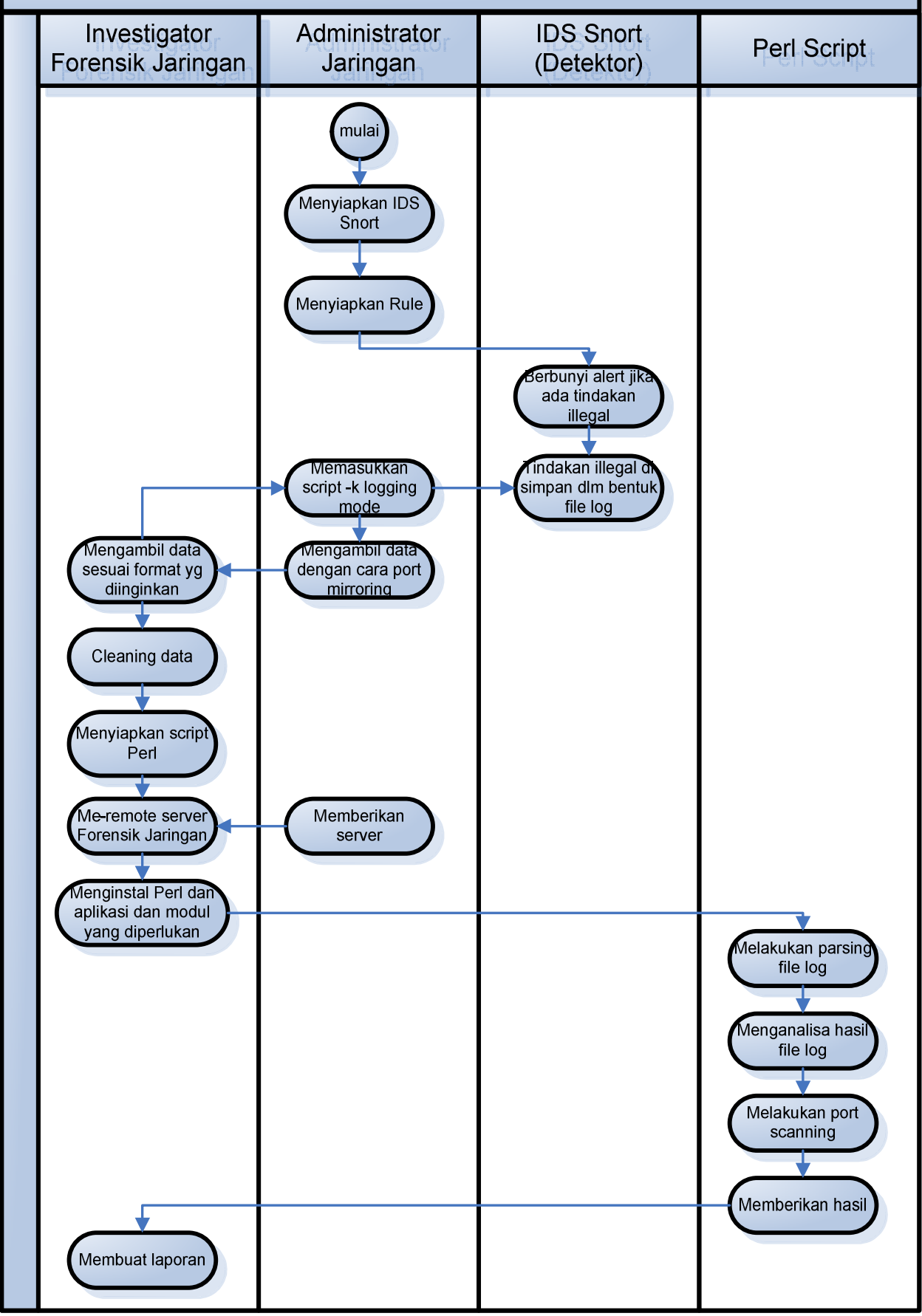

Gambar 2.4. Diagram aktivitas penelitian 